\title{
Concentration of active sludge in the aeration reactors
}

\author{
Nina Zaletova* and Nadezhda Morozova \\ Moscow State University of Civil Engineering, Department Of Water Supply And Wastewater \\ Treatment, 26, Yaroslavskoye shosse, Moscow, Russia, 129337
}

\begin{abstract}
The purpose of the paper was to study the dehydrogenase activity (DHA) of activated sludge in aeration tank. The article describes a change in enzyme activity, (dehydrogenase activity of sludge-DHA) of activated sludge while various time of aeration as well as various dose in sludge of aeration tank. Assessment changes enzyme activity were done on two indicators - on DHA or. (original dehydrogenase activity of sludge) and $\mathrm{DHAH}_{2} \mathrm{O}$ (dehydrogenase sludge activity with tap water). In the first case DHA with the actual substrate, in the second case - DHA with poorly concentrated substrate. The work was performed on a pilot installation consisting of four models of aeration tanks blocked with sedimentation tanks, on a real city waste water. Working doses of sludge in biological wastewater treatment process was ranged from 2 to $6 \mathrm{~g} / \mathrm{l}$, time of aeration in aeration tanks changed from 3.5. up to 0.8 hours. Experimental studies have shown that regardless of the size of working sludge dose in aeration tank character of changes DHA or and $\mathrm{DHAH}_{2} \mathrm{O}$ is identical.
\end{abstract}

\section{Introduction}

Biological treatment of urban wastewater and of wastewaters other types with close composition in artificial constructions, due to its universality, extended now, and will remain in the future the main method of treatment. The traditional method of purification allows achieving the level of biological purification with parameters of biochemical oxygen demand (BOD) and suspended solids $10-15 \mathrm{mg} / \mathrm{l}$. To perform additional tasks to improve the cleaning of specific pollutants that cannot be done by biological way, technological schemes need to complement by physical and chemical or any other methods.

In bioremediation of pollutants treatment of wastewater is produced by activated sludge. Removal of contaminants by activated sludge represents a step-like technology, including sorption and oxidation stages [1-6]. In the biochemical oxidation, organic matter generally lose electrons in the form of hydrogen atoms. One of the key enzymes involved in the cleanup process is dehydrogenase. Dehydrogenase is presented in all living cells, and involves in the reactions of carbohydrate and lipid metabolism. Dehydrogenase activity is to transfer the hydrogen atoms to the link with atoms oxygen prior to the formation of water or with the formation of hydrogen gas [7-9].

${ }^{*}$ Corresponding author: naz1604@yandex.ru 
Our task was to find a correlation between the values of the dose of activated sludge and dehydrogenase activity (DHA) of this sludge for the period of different time of water treatment and different doses of activated sludge in the aeration tanks.

\section{Materials and methods}

Studies were conducted on a pilot installation, working in real conditions flowing urban wastewater. Experimental setup consisted of four parallel running model aeration sedimentation tanks (I-IV). Each aeration -sedimentation tank had the aeration zone with volume - 81 and zone for sedimentation- with volume 21. Pilot installation worked on real flowing urban wastewater $[10,11]$.

Feeding of wastewater produced from single source of municipal raw wastewater. Independent dosing system of wastewater was installed in each certain aeration tank. Wastewater consumption, which was supplied in each aeration -sedimentation tank, was measured by volumetric method. For aeration sludge in aeration tank was supplied air through ceramic devices. Amount of air not limited biological oxidation processes. Quantity of air was controlled in each aeration tank with special devices - rotameters.

With a view to sludge aeration supplied air through ceramic aerators, not limiting biological oxidation processes. Wastewater supply was carried out volumetric method, air consumption - rotameter.

For aeration sludge, air is supplied through ceramic aerators. Quantity of air did not limit biological oxidation processes. Consumption of water in each model was measured by volumetric method; air consumption was measured by rotameter.

Scheme of pilot plant is presented in Figure 1.

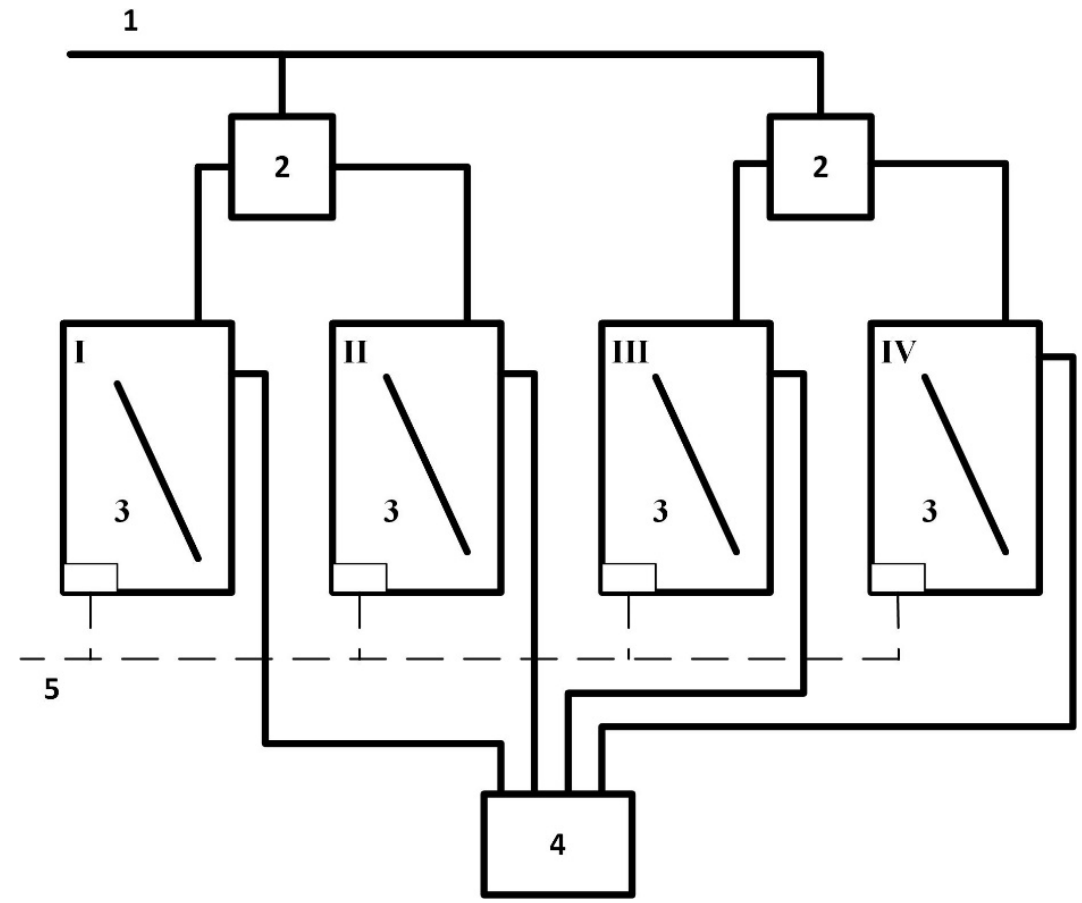

Fig. 1. Technological scheme of the experimental setup: 1- effluent; 2-distribution containers; 3models of aeration-sedimentation tanks; 4 reset purified water in the sewers; 5-air supply. 
The original wastewater from a common feeding pipeline of water city sewer 1 enrolled in four parallel in work pilot aeration tanks- (I-IV) through distribution bins 2 and aerated. Activated sludge separated and treated waste reset the drain 4 . Zone of aeration were supplied with air 5

Biological treatment processes have been held at the same wastewater in the aeration tanks with various sludge doses in each tank. Time of aeration in each tank was an distinct and constantly maintained at a fixed level. Conditions of experiments are listed in Table 1.

Table 1. Basic parameters for the conduct of research the biological process on experimental setup.

\begin{tabular}{|c|c|c|c|c|}
\hline Model & Wastewater flow $[\mathrm{l} / \mathrm{d}]$ & Time of aeration $[\mathrm{h}]$ & MLSS [g/l] & \\
\hline I & 54 & 3.6 & $2.0-5.0$ & \\
\hline II & 108 & 1.8 & $2.0-6.0$ & \\
\hline III & 144 & 0.9 & $1.5-6.0$ & \\
\hline IV & 359 & 0.5 & $1.7-5.3$ & \\
\hline
\end{tabular}

From the data given in the Table 1 it follows that each of the aeration tanks was supplied the installed water consumption. Time of aeration varied from 0.5 up to 3.6 hours. In each of aeration tanks; working dose of the active sludge in the course of the experiment varied in the range of $2 \mathrm{~g} / \mathrm{l}$ up to $6 \mathrm{~g} / \mathrm{l}$.

Samples of original effluents and treated wastewater in each aeration tank monitored by indicators of BOD, COD, and suspended solids concentrations. Activated sludge in each aeration tank was determined by the dose of the active sludge, ash, and sludge index and dehydrogenase activity. Samples of effluents and treated sewage as well as samples of sludge were selected for chemical analysis from each of the models after introduction of the aeration tank to the specified mode. The following indicators characterized the original wastewater: $\mathrm{BOD}_{5}$ 90-150 mg/l, concentrations of suspended solids 70-90 mg/l, chemical oxygen demand (COD) $225-332 \mathrm{mg} / 1$, total phosphorus $12-20 \mathrm{mg} / 1$ (as $\mathrm{PO}_{4}$ ).

To determine dehydrogenases activity of samples of sludge the colorimetric method based on Triphenyl-tetrazolium chloride (TTC) was used. The principle of method consists in reduction of uncolored TTC to red colored formazan under action of hydrogen transferred from dehydrogenases, extraction of it with organic solvents (ethanol, methanol and acetone) and spectrophotometric detection (485 nm wave length). So color intensity is proportional with dehydrogenases activity. Analysis of DHA and assess obtained results was performed on methods [11]. Installed value of the original DHA $\left(\mathrm{DHA}_{\mathrm{or}}\right)$ and dehydrogenase activity with tap water, i.e. with the substrate with small concentration $\left(\mathrm{DHA}_{\mathrm{H} 2 \mathrm{O}}\right)$.

Load of organic matter on active sludge - $\mathrm{N}$ - in each case [11] calculated according to the formula:

$$
N=\frac{24 \times\left(L_{e n}-L_{e x}\right)}{a_{i} \times(1-s) \times t_{a t}}
$$

Where $\mathrm{L}_{\mathrm{en}}, \mathrm{L}_{\mathrm{ex}}$ - BOD entering the bioremediation wastewater [mg/l].

$\mathrm{a}_{\mathrm{i}}$-dose of sludge in the aeration tank $[\mathrm{g} / \mathrm{l}]$.

s-ash of sludge;

$\mathrm{t}_{\mathrm{at}}$-aeration time $[\mathrm{h}]$.

\section{Results}

Technological parameter of work- load of organic matter on active sludge in aeration tank is widely used for the assessment of the nature of biochemical process in aeration tank [11]. Load is indicating of the effectiveness of the biological treatment. High load is provided 
incomplete biological purification. A consequence of the reducing of load leads to improvement the quality of wastewater from organic and suspended solids.

For the activated sludge characteristics according to method of determination DHA it is necessary to define two indicators of the one sample of activated sludge-DHA $\mathrm{A}_{\text {or }}$ and $\mathrm{DHA}_{\mathrm{H} 2 \mathrm{O}}$, and then compare these values. The correlation between $\mathrm{DHA}_{\text {or }}$ and $\mathrm{DHA}_{\mathrm{H} 2 \mathrm{O}}$, when $\mathrm{DHA}_{\text {or }}>\mathrm{DHA}_{\mathrm{H} 2 \mathrm{O}}$ characterizes biological system with the unfinished wastewater treating process, $\mathrm{DHA}_{\mathrm{H} 2 \mathrm{O}}=\mathrm{DHA}_{\text {ish }}$ is evidence of completion of withdrawal organic pollutants, the ratio $\mathrm{DHA}_{\mathrm{H} 2 \mathrm{O}}>\mathrm{DHA}_{\text {or }}$ indicates that it goes regeneration of activated sludge. For steam units $\mathrm{DHA}_{\text {or }}$ and $\mathrm{DHA}_{\mathrm{H} 2 \mathrm{O}}$ for each sample sludge load on active silts is defined, where it worked at the time of sample aeration tank sludge.

The results of the experiment were combined into three groups with doses of sludge in aeration tanks: 2-2,5 g/l, 3-4 g/l and 5-6g/1/ Then dependencies both values DHA from the corresponding loads on active sludge was done.

Dependence of $\mathrm{DHA}_{\text {or }}$ and $\mathrm{DHA}_{\mathrm{H} 2 \mathrm{O}}$ from loading on activated sludge by organic substances with different doses of sludge shown in Figure 1. The graph a) covered changes values $\mathrm{DHA}_{\text {or }}$ and $\mathrm{DHA}_{\mathrm{H} 2 \mathrm{O}}$ from the load with doses of sludge 2-2,5 g/l; chart b) reflects changes in the $\mathrm{DHA}_{\text {or }}$ and $\mathrm{DHA}_{\mathrm{H} 2 \mathrm{O}}$ at operating doses of sludge 3.5-4.0 g/l; on the chart c) with $\mathrm{DHA}_{\text {or }}$ and $\mathrm{DHA}_{\mathrm{H} 2 \mathrm{O}}$ dependency of the load when working aeration tank with doses of sludge 5.0-6 g/l. On the $\mathrm{x}$-axis shows the load on organic substance, on the y-axis shows values $\mathrm{DHA}_{\text {or }}$ and $\mathrm{DHA}_{\mathrm{H} 2 \mathrm{O}}$.

Analysis of the data shows that, despite the magnitude of the dose of sludge in aeration tank, working reduced load on active sludge is accompanied by the reduction of both indicators of DAI. In doing so, regardless of the dose of active sludge in the workspace area with elevated loads on active sludge (i.e. on the right side and schedules a), b), c), curve $\mathrm{DAI}_{\mathrm{or}}$ is placed above the curve describing $\mathrm{DAI}_{\mathrm{H} 2 \mathrm{O}}$. As the organic load on sludge was decreased the gap in concentrations $\mathrm{DAI}_{\mathrm{or}}$ and $\mathrm{DAI}_{\mathrm{H} 2 \mathrm{O}}$ was reduced.

Qualitative change ratios values DHA passes through the point where DHAor = DHA $_{\mathrm{H} 2 \mathrm{O} \text {. }}$

a) $\mathrm{a}_{\mathrm{i}}=2,0-2,5 \mathrm{~g} / \mathrm{l}$;

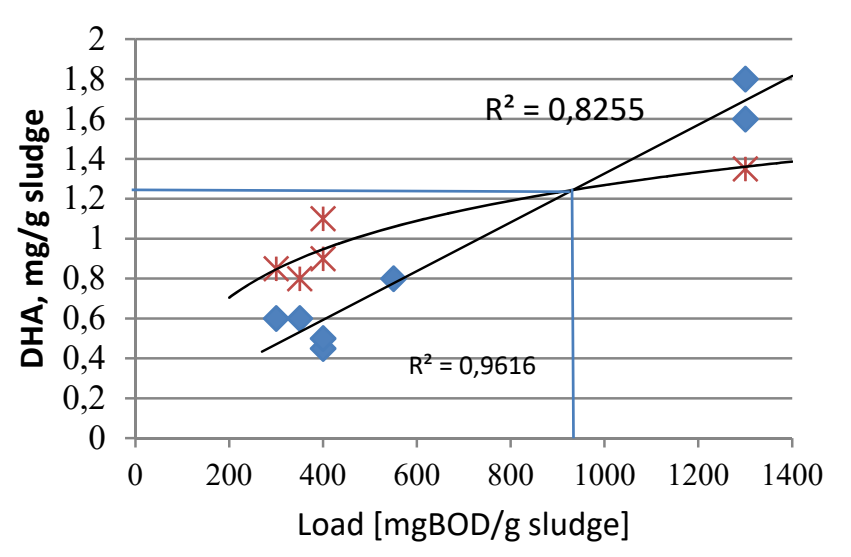

DHAor $* \mathrm{DHAH} 2 \mathrm{O}$ 
b) $\mathrm{a}_{\mathrm{i}}=3,0-4,5 \mathrm{~g} / 1$

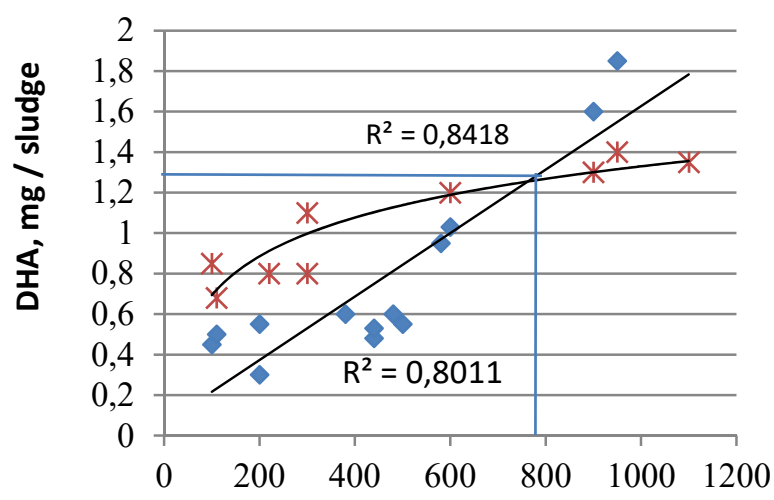

Load [mgBOD/g sludge]

- DHAor $*$ DHAH2O

c) $a_{i}=5-6,5 \mathrm{~g} / 1$

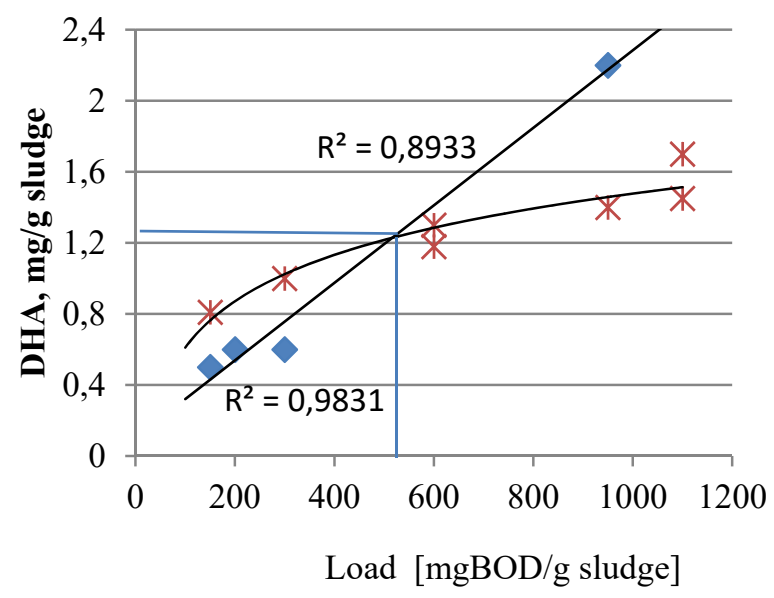

$\diamond$ DHAor $*$ DHAH2O

Fig. 2. Influence of load on active sludge on the value of DHAor and $\mathrm{DHA}_{\mathrm{H} 2 \mathrm{O}}$ at operating doses of sludge in the aeration tank: a) 2-2.5 g/l; in) 3.0-4.5 g/l; c) 5-6.5 g/l.

In the left zone of charts, i.e. in the area with much lower loads of organic substances, $\mathrm{DHA}_{\text {or }}$ curve was placed below the curve $\mathrm{DHA}_{\mathrm{H} 2 \mathrm{O}}$ on all charts. While the size of load decreased the rupture $\mathrm{DHA}_{\text {or }}$ and $\mathrm{DHA}_{\mathrm{H} 2 \mathrm{O}}$ increased.

Dependencies characterize the qualitative change in the nature of wastewater treatment and according to the aforementioned methodology [11] confirm serial passage of sorption and oxidation wastewater treatment processes. It should be noted that for all cases examined, intersection curves $\mathrm{y}$-axis values DAIish and $\mathrm{DHA}_{\mathrm{H} 2 \mathrm{O}}$ almost close and 
represented about $1.22 \mathrm{mg} / \mathrm{g}$ DHA sludge in all cases when reaching a certain specific values DHA regardless working dose silt in aeration tank.

\section{Conclusions}

1. Experimental studies show that the nature of the changes $\mathrm{DHA}$ or and $\mathrm{DHA}_{\mathrm{H} 2 \mathrm{O}}$ for active sludge, working with various specific doses of sludge, is identical. As you reduce the load on sludge DHA smoothly reduced.

2. Change indicator DHA confirmed that biological treatment is a gradual purifying of organic pollutants. While cleaning stages occur sequentially, moving from one stage to another passes through the point of intersection of the curves,. i.e. the conditions under which the concentration of $\mathrm{DHA}_{\mathrm{or}}=\mathrm{DHA}_{\mathrm{H} 2 \mathrm{O}}$.

3. The intersection of curves occurs when a certain size DHA reached regardless working dose silt in aeration tank. In the experiment in the processing of specific wastewater value stride crossing point was $1.22 \mathrm{mg} / \mathrm{l}$.

4. It is possible to use the DHA indicators for operational control of biological treatment plants.

\section{References}

1. N.A. Bazjakina, The role of activated sludge in the aeration tank work for complete cleaning (Union central, Moscow, 1936)

2. S.V. Yakovlev, T.A. Karjuhina, Biochemical processes in wastewater treatment. Water and sanitary equipment (Stroyizdat, Moscow, 1982)

3. Mishukov B.G., Protasovskij E.M. Description of progress in biological treatment on two-stage model of enzymatic reactions (LISI works, Leningrad, 1982)

4. Shvetsov V.N. Morozova, K.M., Zakharova O.E., Petrova L.A. Prospects of application of bisosorbtion method of wastewater treatment (VNII VODGEO, Moscow, 1986)

5. I.M. Tavartkiladze, Sorption processes in biofilters (Stroyizdat, Moscow, 1989)

6. Paal L. 1., Karu Y. y.,. Melder H.A, Repin B.N. Natural and waste water purification (NIS, Moscow, 1994)

7. J. Bailey, D. Ollis Basis Biochemical engineering (Mir, Moscow, 1989)

8. Golubovskaya E.K. Biological bases of water purification (High school, Moscow, 1978)

9. Taube P.R., Baranova A.G., Chemistry and microbiology of water (High school, Moscow, 1983)

10. Lipman B.L., Zaletova N.A., Melzer V.Z. Artamonov V.I. High performance biological cleaning in the scheme of deep treatment of wastewater (CINIS Gosstroy, Moscow, 1987)

11. Zaletova N.A., Grebenevich E.V., Terentieva N. Municipal Waste Water Treatment for Effective Removal of Organic Matter and Nitrogen (Visby, Helsinki, 1987) 